\title{
KENYAMANAN PEJALAN KAKI TERHADAP PEMANFAATAN TROTOAR DI JALAN BRIGJEN KATAMSO MEDAN
}

\author{
Rina Saraswaty \\ Dosen Pengajar Program Studi Arsitektur, Fakultas Teknik Universitas Medan Area \\ (rinasaraswaty@yahoo.co.id)
}

$\begin{array}{ll}\text { Diterima } & : \text { 17 Januari } 2017 \\ \text { Disetujui } & : 28 \text { Februari } 2017\end{array}$

\begin{abstract}
ABSTRAK
Medan merupakan salah satu kota besar di Indonesia yang memiliki tingkat kepadatan lalu lintas yang tinggi. Tingginya kepadatan lalu lintas menimbulkan banyak permasalahan, baik dari segi ekonomi, sosial dan keamanan serta kenyamanan. Permasalahan tersebut muncul akibat dari kebijakan-kebijakan pemerintah didalam membuat peraturan sistem transportasi dan sistem lalu lintas dalam tata ruang perkotaan. Karena didalam membuat kebijakan tata ruang suatu perkotaan seharusnya mengikutsertakan seluruh pihak yang terkait, baik pihak swasta, masyarakat dan pemerintah. Disamping itu dapat juga bersumber dari perilaku manusia itu sendiri yang kurang disiplin didalam mematuhi peraturan yang ada. Secara umum, trotoar di kota Medan sebagai jalur transportasi pejalan kaki telah bergeser fungsinya menjadi fungsi yang lain. Tujuan penelitian ini adalah untuk mengetahui sejauh mana trotoar yang berfungsi sebagai jalur transportasi pejalan kaki telah beralih fungsi menjadi fungsi lain. Metode yang digunakan dalam pengumpulan data melalui kuesioner terhadap responden penelitian yaitu pejalan kaki. Daerah penelitian yang diambil adalah sepanjang jalur pedestrian Jalan Brigjend Katamso dimulai dari simpang Jalan Pandu - Jalan Letjen Soeprapto (simpang Waspada) hingga simpang Jalan AH. Nasution (simpang Titi Kuning) Medan. Luaran penelitian ini diharapkan dapat menjadi masukan bagi pemerintah dalam membuat kebijakan publik khususnya jalur transportasi pejalan kaki dan artikel ilmiah pada Jurnal Lokal ber-ISSN.
\end{abstract}

Kata Kunci : Lalu Lintas, Jalur Transportasi, Pejalan Kaki

\begin{abstract}
Medan is one of the big cities in Indonesia that has a high traffic density. The high traffic density poses many problems, both in terms of economic, social and security as well as convenience. These problems arise as a result of policies. Because in making a spatial policy a place that should include all relevant parties, both private parties, communities and governments. Besides, it can also be derived from human behaviour itself is less discipline in the existing regulations. In general, sidewalks in the city of Medan as a pedestrian transport path have shifted their function into other functions.

The purpose of this research to find out which sidewalks serve as pedestrian transport routes that have become other functions. The method used in completion of data through questionnaires to the research respondents ie pedestrians. The research area is taken along the pedestrian path of Jalan Brigjen Katamso starting from the intersection of Jalan Pandu - Jalan Letjen Soeprapto (intersection Waspada) to intersection of Jalan AH. Nasution (intersection of Titi Kuning) Medan. The output of this research is expected to be an input for the government in terms of honesty public specialist in pedestrian transportation and scientific articles in ISSN Local Journal.
\end{abstract}

Keywords: Pedestrian Transport Routes, Safety and Comfort,Traffic 


\section{Pendahuluan}

Perkembangan kota di satu sisi sangat terkait pada faktor penduduk disamping faktor ketersediaan lahan dan sarana serta prasarana. Di satu sisi perkembangan kota sangat terkait pada faktor penduduknya dan di sisi lain juga tergantung kepada daya dukung lahan dan kemampuan daerah ditinjau dari segi pendanaan atau anggaran biaya daerah tersebut (Hakim dan Utomo, 2003:2). Sementara perkembangan kota juga tidak terlepas dari penempatan sarana yang diperuntukkan bagi masyarakat guna memenuhi kebutuhan hidup, baik yang diselenggarakan oleh pemerintah maupun swasta. Karena didalam membuat kebijakan tata ruang kota harus mengikutsertakan seluruh pihak terkait, baik swasta, masyarakat maupun pemerintah.

Kota sebagai pusat kegiatan sangat membutuhkan sarana dan prasarana perhubungan yang memadai untuk menjangkau semua tempat kegiatan yang dibutuhkan. Demikian halnya dengan Kota Medan yang merupakan salah satu kota besar di Indonesia memiliki jumlah penduduk yang besar membutuhkan sarana dan prasarana perhubungan yang baik dan memadai untuk melayani sistem transportasi kota. Seperti halnya kota besar lainnya di Indonesia, Kota Medan memiliki masalah dalam sistem perhubungan, yaitu:

a. Belum tersedianya sarana dan prasarana jalan yang memadai, seperti kelengkapan marka jalan, pemberhentian angkutan umum atau halte bis, jalur trotoar yang baik.

b. Kepemilikan kenderaan pribadi yang melebihi kapasitas sehingga mengakibatkan kemacetan lalu lintas.

c. Jumlah panjang $\mathrm{km}$ jalan yang belum memadai.

Jalan merupakan sarana perhubungan yang vital dan perlu untuk mendapat perhatian yang serius sehingga aktifitas transportasi orangorang yang ada di dalam suatu kota menjadi lebih baik dan lancar. Untuk itu, pembangunan jalan yang terkonsep dan terencana dengan baik sangat diperlukan. Trotoar merupakan bagian dari rekayasa jalan raya yang diperuntukkan khusus untuk pejalan kaki (pedestrian). Trotoar harus disediakan pada bagian jalan raya dengan ketentuan jumlah minimal 300/12 jam pejalan kaki dan 1000/12 jam bagi kenderaan yang melintasi jalan tersebut.

Namun pada kenyataannya, kebanyakan trotoar tidak lagi berfungsi sebagaimana mestinya. Trotoar tidak lagi berfungsi sebagai fasilitas jalan kota bagi pejalan kaki tetapi telah beralih fungsi untuk aktifitas lainnya. Jalan Brigjen Katamso merupakan salah satu kawasan wisata bagi pejalan kaki di kota Medan, disamping sebagai daerah atau kawasan usaha dan bisnis di kota Medan. Kawasan dengan pemandangan bangunan kuno peninggalan sejarah masa lalu dapat dinikmati dengan berjalan kaki. Namun kondisi ini tidak dapat sepenuhnya dinikmati karena adanya pergeseran fungsi pedestrian di kawasan ini, sehingga pejalan kaki kurang dapat menikmati suasana warisan budaya kota Medan tersebut.

Dari latar belakang tersebut diatas, maka permasalahan yang diangkat pada penelitian ini adalah apakah trotoar di sepanjang Jalan Brigjen Katamso (dari simpang Jalan Letjen Soeprapto-Pandu hingga Simpang Jalan AH. Nasution) berfungsi sesuai dengan fungsi sebenarnya sebagai jalur transportasi bagi pejalan kaki. Hal ini perlu diketahui karena selama ini telah terjadi pergeseran fungsi trotoar sehingga tidak memberikan keamanan dan kenyamanan bagi pejalan kaki.

Adapun tujuan dari penelitian ini adalah untuk mengetahui sejauh mana trotoar di sepanjang Jalan Brigjen Katamso telah berfungsi dengan sebenarnya sebagai jalur transportasi khusus bagi pejalan kaki ditinjau dari segi keamanan dan kenyamanan.

\section{Kajian Teori}

\subsection{Sirkulasi dan Keamanan}

Jalan berperan sebagai prasarana lalu lintas dan ruang transisi (transitional space), selain itu juga tidak tertutup kemungkinan sebagai ruang beraktifitas (activity area) yang merupakan ruang terbuka untuk kontak sosial, wadah kegiatan. Kenyamanan suatu ruang akan berkurang akibat dari sirkulasi yang tidak tertata dengan baik. Untuk itu perlu penataan ruang yang fungsionalitas demi terciptanya kelancaran aktifitas sirkulasi, baik sebagai ruang transisi maupun ruang beraktifitas. 
Penataan sistem sirkulasi antar ruang, terutama dalam hal penempatan serta penggunaan fungsi yang tepat sangat mempengaruhi kenyamanan pola pergerakan antar ruang itu sendiri. Hubungan sirkulasi antar ruang yang tidak komprehensif serta tanpa koordinasi dapat mengakibatkan sirkulasi antar ruang yang kurang nyaman bagi penggunanya. Karena kenyamanan adalah segala sesuatu yang memperlihatkan penggunaan ruang secara sesuai dan harmonis baik dengan ruang itu sendiri maupun dengan faktor lainnya, seperti bentuk, tekstur, warna, tanda, suara maupun cahaya (Rustam Hakim dan Hardi Utomo, 2003:185).

Menurut Tanudjaja (Pamungkas, 2003:19), bahwa manusia memiliki jenjang kebutuhan yang salah satunya adalah kebutuhan rasa aman (safety need) yang berkaitan dengan keselamatan dan keamanan. Keamanan merupakan masalah yang mendasar karena mampu menghambat aktifitas yang dilakukan. Keamanan bagi pejalan kaki dan kenderaan bermotor dapat tercapai dengan baik jika ada suatu kejelasan didalam pembagian sirkulasi. Perencanaan keamanan pejalan kaki dapat dilakukan dengan menyediakan fasilitas pedestrian, yaitu jalur trotoar.

Menurut Ian Bentley (1988:70), bahwa hampir semua jalan dirancang untuk penggunaan gabungan dari kendaraan bermotor dan pejalan kaki. Oleh karena itu, jalan hendaknya dirancang terperinci sehingga kenderaan bermotor tidak akan mengalahkan pejalan kaki. Karena fungsi jalan sangat berpengaruh terhadap proses aktifitas pergerakan manusia.

Untuk keamanan pejalan kaki, maka trotoar harus dibuat terpisah dari jalur kenderaan bermotor, dengan lebar trotoar yang dibutuhkan oleh volume pejalan kaki, tingkat pelayanan pejalan kaki dan fungsi jalan adalah dengan lebar 1,5 - 3,0 meter. Antara zona pejalan kaki dengan ruang kenderaan harus disediakan daerah untuk fasilitas pejalan kaki, seperti pohon peneduh, shelter, tempat duduk dan fasilitas lainnya

\subsection{Pejalan Kaki dan Trotoar}

Dirjen Perhubungan Darat (1993:205) menyatakan bahwa pejalan kaki adalah suatu bentuk transportasi yang penting di perkotaan. Pejalan kaki merupakan kegiatan yang cukup esensial dari sistem angkutan dan harus mendapat tempat yang selayaknya. Pejalan kaki pada dasarnya adalah lemah, mereka terdiri dari anak-anak, orang tua dan masyarakat dengan penghasilan kecil.

Pejalan kaki mempunyai hak untuk mendapatkan kenyamanan menggunakan jalan. Pejalan kaki yang tidak mematuhi peraturan merupakan salah satu masalah sistemik dalam sistem transportasi. Jumlah kecelakaan lalu lintas akibat pejalan kaki di Kota Medan masih cukup besar. Hal ini terjadi akibat fasilitas pejalan kaki berubah fungsi menjadi aktifitas lain. Trotoar merupakan fasilitas bagi pejalan kaki, letaknya berdampingan dengan jalur lalu lintas kenderaan. Lebar trotoar menurut Kementerian Perhubungaan No.KM.65 tahun 1993, sebagai berikut :

\section{Tabel 1 Lebar Trotoar Menurut Kementerian Perhubungaan No.KM.65 Tahun 1993}

\begin{tabular}{|l|l|l|}
\hline No & $\begin{array}{l}\text { Lokasi Pengadaan } \\
\text { Trotoar }\end{array}$ & $\begin{array}{l}\text { Lebar } \\
\text { Trotoar } \\
\text { Min. }(\mathrm{m})\end{array}$ \\
\hline 1 & $\begin{array}{l}\text { Jalan di daerah } \\
\text { perkotaan }\end{array}$ & 4,00 \\
\hline 2 & $\begin{array}{l}\text { Wilayah perkantoran } \\
\text { utama }\end{array}$ & 3,00 \\
\hline 3 & Wilayah industri & 3,00 \\
\hline & a. Jalan primer & 2,00 \\
\hline 4 & b. Jalan akses & Wilayah pemukiman \\
\hline & a. Jalan primer & 2,75 \\
\hline & b. Jalan akses & 2,00 \\
\hline
\end{tabular}

Sumber: Direktorat Jenderal Bina Marga, 1999

\section{Metodologi Penelitian}

Pada penelitian ini obyek pengamatan dilakukan di sepanjang Jalan Brigjen Katamso, dimulai dari simpang Jalan Letjen Soeprapto Jalan Pandu hingga persimpangan Jalan AH. Nasution (simpang Titi Kuning) Medan. Waktu penelitian direncanakan pada bulan Agustus hingga Desember 2016, dengan tahapan sebagai berikut : 
a. Survey awal (survey lokasi), dilakukan untuk memetakan lokasi yang akan dijadikan sebagai obyek pengamatan.

b. Survey lanjutan, berupa pengarahan bagi responden di lokasi pengamatan dengan membagikan kuesioner.

c. Pengumpulan data primer, melakukan pengamatan dan pemotretan terhadap obyek pengamatan di lokasi penelitian dalam waktu terbatas.

d. Mendata hasil pengamatan yang telah dilakukan sesuai dengan petunjuk yang ada pada lembaran kuesioner yang diberikan.

e. Pengolahan data yang telah diperoleh dengan menganalisa untuk selanjutnya dibuat dalam bentuk laporan.

Penelitian ini menggunakan metode pengumpulan data langsung di lapangan melalui pengamatan dan pemotretan terhadap obyek pengamatan dengan panduan kuesioner yang ada. Hasil pengamatan dan pemotretan didata untuk kemudian hasilnya ditabulasikan dan dianalisa

\section{Hasil dan Pembahasan}

\subsection{Kondisi Umum dan Aktifitas Kawasan}

Pertumbuhan Kota Medan yang pesat dipengaruhi oleh tingkat urbanisasi dan kemajuan teknologi dimana pada dasarnya tumbuh secara alami sehingga mempersulit pengalokasian suatu kegiatan yang homogen. Salah satu penyebabnya adalah akibat adanya penggunaan lahan (land use) yang berkembang tidak beraturan. Pada umumnya pengaturan dan pemanfaatan land use masih dititikberatkan pada persoalan-persoalan fisik, sosial, politik dan ekonomi masyarakat.

Perkembangan Kota Medan berkaitan erat dengan sistem jaringan prasarana jalan dimana sistem pergerakan sangat dipengaruhi oleh sistem tat guna lahan dan sistem sarana transportasi. Jaringan jalan dianggap urat nadi yang menghubungkan satu tempat dengan tempat lainnya. Pola jaringan jalan di setiap kota berbeda dikarenakan pola intensitas tata guna lahan (land use) dan kondisi geografi. Jalan merupakan sarana vital yang perlu mendapat perhatian serius agar aktifitas manusia didalamnya menjadi lebih akselertif. Untuk itu, pembangunan jalan yang terkonsep dan terencana dengan baik sangat diperlukan. Menurut Peraturan Geometrik Jalan Raya No. 13/1970, menurut fungsinya, jalan raya pada umunya dapat diklasifikasikan menjadi tiga golongan, yaitu:

a. Jalan Utama; jalan raya yang melayani lalu lintas yang tinggi antara kota-kota penting atau antara pusat-pusat produksi dan pusat keramaian.

b. Jalan Sekunder

c. Jalan Penghubung

Aktifitas masyarakat untuk menjangkau suatu tempat atau kegiatan dapat dilakukan dengan dua cara, yaitu dengan menggunakan kenderaan dan berjalan kaki. Bagi pemakai kenderaan telah disediakan jalur-jalur jalan, sedangkan untuk pejalan kaki telah disediakan secara khusu jalurnya, yakni trotoar atau pedestrian.

Trotoar merupakan bagian dari rekayasa jalan raya berfungsi sebagai jalur jalan yang khusus diperuntukkan bagi pejalan kaki. Pada penelitian ini mengambil lokasi di Jalan Brigjen Katamso, sebagai jalan protokol dalam Kota Medan dengan tingkat aktifitas kawasan yang cukup tinggi, dimulai dari persimpangan Jalan Pandu-Jalan Letjen Soeprapto (simpang Waspada) sampai persimpangan Jalan AH. Nasution (simpang Titi Kuning) dengan panjang lintasan lebih kurang 5,2 kilometer.

Untuk memudahkan pengamatan, maka lokasi penelitian dibagi atas empat zona jalur, yaitu:

a. Zona A; dimulai dari persimpangan Jalan Pandu-Jalan Letjen Soeprapto sampai persimpangan Jalan Ir. H. Juanda

b. Zona B; dimulai dari persimpangan Jalan Ir. H. Juanda sampai persimpangan Jalan Pelangi

c. Zona C; dimulai dari persimpangan Jalan Pelangi sampai persimpangan Jalan Sakti Lubis

d. Zona D; dimulai dari persimpangan Jalan Sakti Lubis sampai persimpangan Jalan Jendral AH. Nasution.

Berikut aktifitas kawasan zona jalur pengambilan sampel penelitian:

Tabel 1 Aktifitas Kawasan dan Karakteristik Lingkungan

\begin{tabular}{|c|l|l|l|}
\hline Zona & $\begin{array}{c}\text { Panjang } \\
\text { Jalur } \\
\text { Trotoar }\end{array}$ & $\begin{array}{c}\text { Kawasan } \\
\text { dan Batas } \\
\text { Area }\end{array}$ & $\begin{array}{c}\text { Karakteristik } \\
\text { Lingkungan }\end{array}$ \\
\hline A & $\begin{array}{l} \pm 1,2 \\
\text { kilomete }\end{array}$ & $\begin{array}{l}\text { Kawasan } \\
\text { persimpan }\end{array}$ & $\begin{array}{l}\text { Perkantoran, } \\
\text { gedung }\end{array}$ \\
\hline
\end{tabular}




\begin{tabular}{|c|c|c|c|}
\hline Zona & $\begin{array}{c}\text { Panjang } \\
\text { Jalur } \\
\text { Trotoar }\end{array}$ & $\begin{array}{c}\text { Kawasan } \\
\text { dan Batas } \\
\text { Area }\end{array}$ & $\begin{array}{c}\text { Karakteristik } \\
\text { Lingkungan }\end{array}$ \\
\hline & $\mathrm{r}$ & $\begin{array}{l}\text { gan Jl. } \\
\text { Pandu-Jl. } \\
\text { Letjen } \\
\text { Soeprapto } \\
\text { sampai } \\
\text { persimpan } \\
\text { gan Jl. Ir. } \\
\text { H. Juanda }\end{array}$ & $\begin{array}{l}\text { pemerintahan } \\
\text { dan pertokoan }\end{array}$ \\
\hline B & $\begin{array}{l} \pm \quad 2,0 \\
\text { kilomete } \\
\mathrm{r}\end{array}$ & $\begin{array}{l}\text { Kawasan } \\
\text { persimpan } \\
\text { gan Jl. Ir. } \\
\text { H. Juanda } \\
\text { sampai } \\
\text { persimpan } \\
\text { gan Jl. } \\
\text { Pelangi }\end{array}$ & $\begin{array}{l}\text { Perkantoran, } \\
\text { perbelanjaan } \\
\text { dan pertokoan }\end{array}$ \\
\hline $\mathrm{C}$ & $\begin{array}{l} \pm \quad 1,0 \\
\text { kilomete } \\
\mathrm{r}\end{array}$ & $\begin{array}{l}\text { Kawasan } \\
\text { persimpan } \\
\text { gan Jl. } \\
\text { Pelangi } \\
\text { sampai } \\
\text { persimp. } \\
\text { Jl. Sakti } \\
\text { Lubis }\end{array}$ & $\begin{array}{l}\text { Perkantoran, } \\
\text { perbelanjaan, } \\
\text { pendidikan } \\
\text { dan pertokoan }\end{array}$ \\
\hline $\bar{D}$ & $\begin{array}{l} \pm \quad 1,0 \\
\text { kilomete } \\
\mathrm{r}\end{array}$ & $\begin{array}{l}\text { Kawasan } \\
\text { persimpan } \\
\text { gan Jl. } \\
\text { Sakti } \\
\text { Lubis } \\
\text { sampai } \\
\text { persimpan } \\
\text { gan Jl. } \\
\text { AH. } \\
\text { Nasution }\end{array}$ & $\begin{array}{l}\text { Perkantoran, } \\
\text { perbelanjaan, } \\
\text { pendidikan } \\
\text { dan pertokoan }\end{array}$ \\
\hline
\end{tabular}

Sumber : Data penelitian

\subsection{Kenyamanan Pejalan Kaki Ditinjau Dari Aspek Keamanan}

Persepsi pejalan kaki tentang kenyamanan yang ditinjau dari aspek keamanan dalam hal ini adalah keselamatan dari gangguan lalu lintas kenderaan, menurut responden meliputi: a. Pembagian lahan (sirkulasi aktifitas) antara pejalan kaki dengan tempat berjualan Pedagang Kaki Lima

b. Pembagian lahan antara pejalan kaki dengan area parkir

c. Pembagian lahan antara pejalan kaki dengan penempatan taman kota maupun fasilitas umum

d. Penyediaan tempat penyeberangan bagi pejalan kaki pada tikungan dan persimpangan jalan

e. Kontrol pandangan mata bagi pejalan kaki ditinjau dari perletakan fasilitas umum yang dapat menghalangi pandangan mata.

Berikut tabulasi persepsi responden terhadap kenyamanan ditinjau dari aspek keamanan:

Tabel 2 Kenyamanan Ditinjau dari Aspek Keamanan

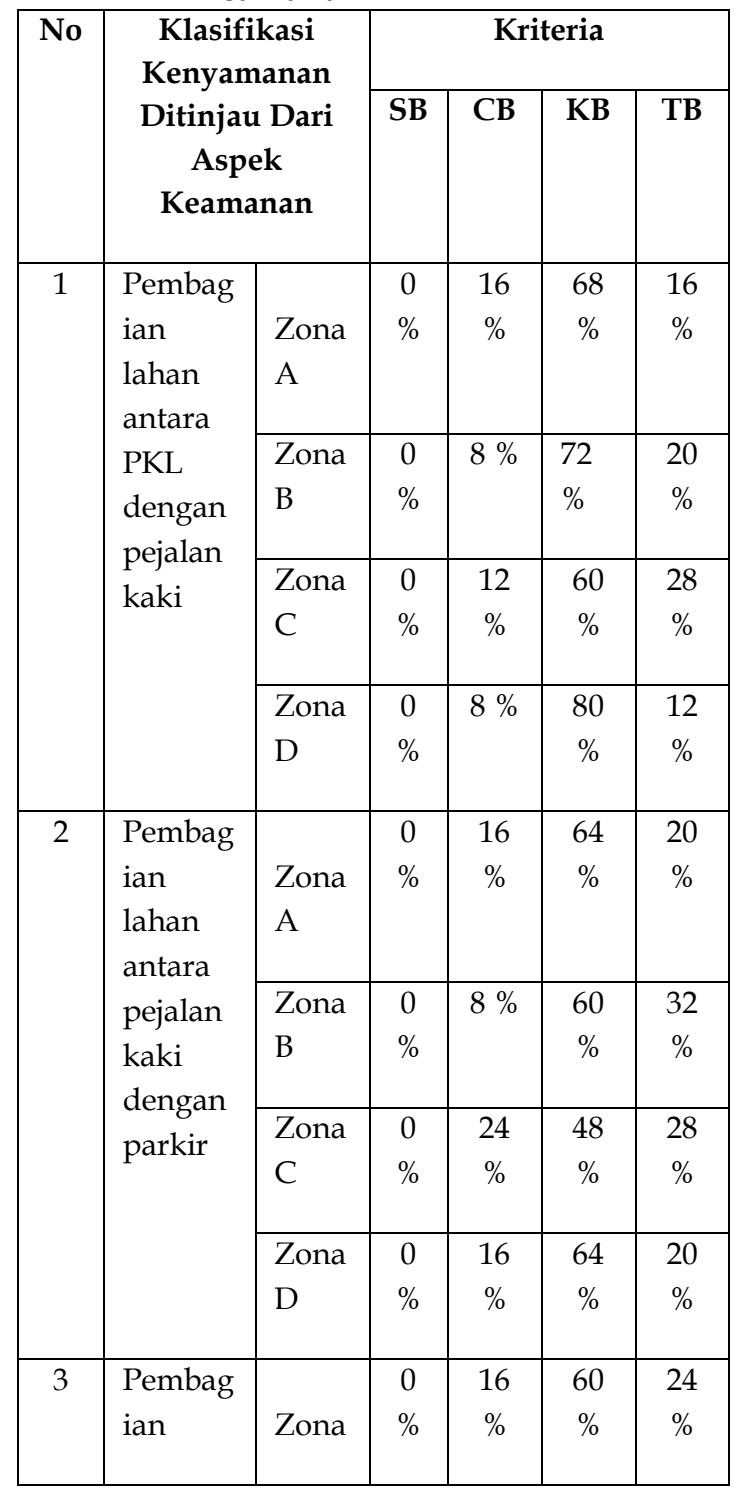




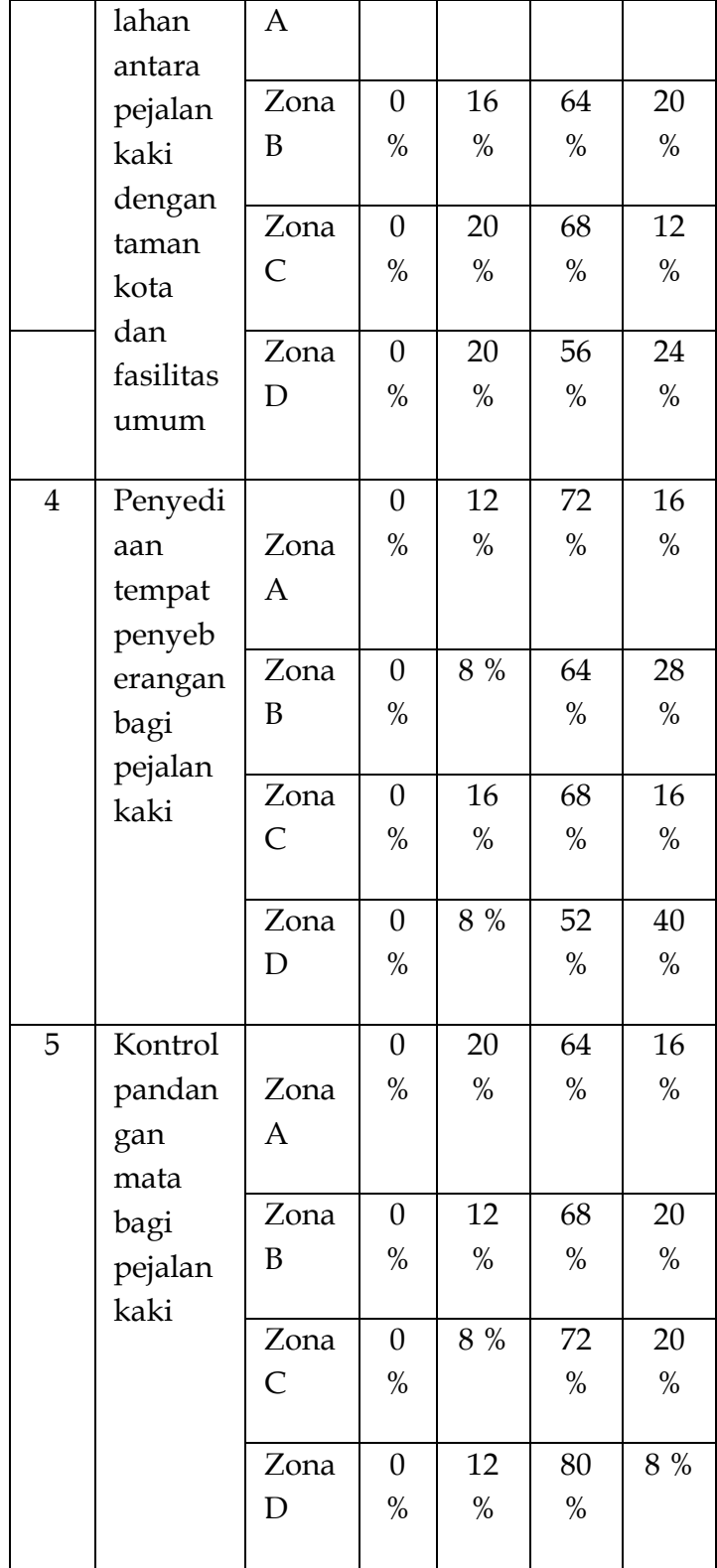

Dari data tersebut diatas, bahwa persepsi kenyamanan ditinjau dari faktor keamanan menunjukkan bahwa dari sejumlah responden yang dipilih, ternyata sebesar 48,20\% menyatakan persepsi yang kurang baik (KB) tentang kenyamanan ditinjau dari aspek keamanan (keselamatan dari gangguan lalu lintas kenderaan). Dimana kenyamanan pejalan kaki akan terganggu jika kurangnya jaminan faktor keamanan dalam pemanfaatan trotoar

\section{KESIMPULAN DAN SARAN}

\subsection{Kesimpulan}

Dari pembahasan diatas tentang kenyamanan pejalan kaki terhadap pemanfaatan trotoar dengan lokasi penelitian di Jalan Brigjen Katamso Medan, maka dapat diambil kesimpulan bahwa dari hasil pendapat responden yang disampel, ternyata pemanfaatan trotoar di sepanjang Jalan Brigjen Katamso tergolong kepada kriteria tingkat kenyamanan yang kurang baik. Hal ini disebabkan karena terjadinya pergeseran fungsi trotoar yang seharusnya sebagai jalur transportasi pejalan kaki berubah menjadi fungsi kegiatan lain, seperti tempat berjualan, tempat usaha lain dan area parkir. Sehingga pejalan kaki terpaksa menggunakan jalur lalu lintas kenderaan untuk berjalan.

\subsection{Saran}

Dari hasil penelitian ini disarankan kepada pemerintah stempat untuk merencnakan dan mengatur ulang secara sitematis sistem jalur transportasi pejalan kaki atau pedestrian di sepanjang Jalan Brigjen Katamso Medan. Penataan ini harus memperhatikan dan mempertimbangkan berbagai aspek kepentingan masyarakat yang dilengkapi dengan fasilitas bagi pejalan kaki sehingga diperoleh trotoar atau pedestrian yang mampu memberikan kenyamanan dan keamanan bagi penggunanya.

\section{Daftar Pustaka}

Bentley, Ian. Alan Alcock, Terjemahan: Lingkungan Yang Tanggap, Pedoman Untuk Perancangan, Abdi Widya, Bandung, 1988

Departemen Perhubungan: Peraturan Pemerintah Republik Indonesia No. 43 Tahun 1993, Tentang Prasarana Lalu Lintas Jalan, Departemen Perhubungan, Jakarta, 1993

Dirjen Bina Marga: Peraturan Perencanaan Geometrik Jalan Raya Nomor 113 Jakarta, 1970

Hakim, Rustam. Hardi Utomo:

Komponen Perancangan Arsitektur Lanskep, Jakarta, 2003

Pamungkas, Widi:Studi Tentang Kenyamanan Aksebilitas Mahasiswa Jurusan Teknik Sipil Unnes Terhadap Gedung Perpustakaan Pusat Unnes.Skripsi FT Unnes, 2003

Sutono, dkk: Rekayasa Jalan Raya, Tugas Akhir, Tugas Akhir Semester. FT Unnes,2002. 